\title{
NOTES
}

\section{Charge-Induced Conformation Change of Xanthan in 0.01 M Aqueous Sodium Chloride}

\author{
Mikihiko NAKASUGA and Takashi NORISUYE \\ Department of Macromolecular Science, Osaka University, \\ Toyonaka, Osaka 560, Japan
}

(Received April 4, 1988)

\begin{abstract}
KEY WORDS Polysaccharide / Xanthan / Conformation Change / Double Helix / Potentiometric Titration /
\end{abstract}

Xanthan is an ionic polysaccharide produced by fermentation with the bacterium Xanthomonas Campestris. This polymer in aqueous salt of low ionic strength undergoes an order-disorder conformation change with increasing temperature $T^{1-3}$ In recent light scattering, viscosity, and optical rotation studies, ${ }^{4-6}$ we showed that the ordered conformation of fully ionized xanthan in $0.01 \mathrm{M}$ aqueous $\mathrm{NaCl}$ at $25^{\circ} \mathrm{C}$ is essentially the same double helix as that found previously by our $^{7-9}$ and other ${ }^{10,11}$ groups at a higher $\mathrm{NaCl}$ concentration $C_{\mathrm{s}}$ of $0.1 \mathrm{M}$ and that its change to the disordered conformation with increasing $T$ is a process of partial melting of the double helix.

In this work, optical rotation, viscosity, and potentiometric titration measurements were made on xanthan with varying degrees of ionization $\alpha$ in $0.01 \mathrm{M}$ aqueous $\mathrm{NaCl}$ at $T$ between 25 and $75^{\circ} \mathrm{C}$. It was found that acid xanthan in the aqueous salt underwent a charge-induced conformation change, i.e., charge-induced helix breaking, when $\alpha$ increased at a fixed $T$ higher than $50^{\circ} \mathrm{C}$. The present paper discusses this finding.

\section{EXPERIMENTAL}

A fractionated xanthan sample X14-2-3 with a weight-average molecular weight $\bar{M}_{w}$ of $7.44 \times 10^{5}$ (in the dimerized acid form) ${ }^{12}$ was used. It was dissolved in deionized water at about $5^{\circ} \mathrm{C}$, and the solution was passed through a mixed-bed ion exchanger (Amberlite IR-120+IRA-410), with the temperature of the solution kept at about $5^{\circ} \mathrm{C}$. To the solution of acid form xanthan thus prepared, aqueous $\mathrm{NaCl}$ was added to obtain an $0.01 \mathrm{M} \mathrm{NaCl}$ solution of the polyacid.

The solution was divided into several parts, and each $\left(10 \mathrm{~cm}^{3}\right)$ was titrated at a given $T$ under a nitrogen atmosphere with $0.100 \mathrm{~N}$ $\mathrm{NaOH}$ containing $0.01 \mathrm{M} \mathrm{NaCl}$. The titrant was delivered by using a Gilmont digital microburet (Type $\mathrm{S} 4100 \mathrm{~A}, 0.25 \mathrm{~cm}^{3}$ in capacity). The concentration $c_{\mathrm{p}}$ of carboxylic acid groups was evaluated from that of $\mathrm{NaOH}$ in the solution at the end of the titration. The degree of ionization was determined in the manner ${ }^{13}$ described elsewhere. The $\mathrm{pH}$ meter (Beckman $\phi 70)$ used was calibrated at each temperature with standard buffer solutions $(\mathrm{pH}=4.01$ and 6.86 at $25^{\circ} \mathrm{C}$ ).

Solutions of partially or completely neutralized xanthan were similarly prepared at given $T$, and their specific rotations $[\alpha]_{300}$ at $300-\mathrm{nm}$ wavelength and relative viscosities $\eta_{\mathrm{r}}$ at zero shear rate were determined as functions of $\alpha^{\prime}$ (the degree of neutralization), $\alpha$, and $T$. For 
the former, a JASCO ORD/UV-5 spectropolarimeter with $10-\mathrm{cm}$ cylindrical quartz cells was used and for the latter, low-shear four-bulb capillary viscometers. The polymer mass concentration $c$ was calculated from $c_{\mathrm{p}}$; the number of charges per repeating unit of our xanthan sample in the fully ionized state is $1.34 .^{13}$ It was found previously ${ }^{5}$ that $[\alpha]_{300}$ of $\mathrm{Na}$ xanthan in $0.01 \mathrm{M}$ aqueous $\mathrm{NaCl}$ is virtually independent of $c$ below $3 \times 10^{-3} \mathrm{~g} \mathrm{~cm}^{-3}$ at any $T$ between 25 and $80^{\circ} \mathrm{C}$. On the basis of this finding, all the optical rotation data given below were taken at $c \sim 1.7 \times 10^{-3} \mathrm{~g} \mathrm{~cm}^{-3}$.

As has been demonstrated by light scattering, ${ }^{4-7,9-11}$ viscosity, ${ }^{5,8,9}$ and sedimentation velocity, ${ }^{9}$ the double-helical structure of $\mathrm{Na}$ xanthan in 0.01 or $0.1 \mathrm{M}$ aqueous $\mathrm{NaCl}$ is characterized by $M_{\mathrm{L}}$ (the molar mass per unit contour length) $=1940 \pm 100 \mathrm{~nm}^{-1}$, which corresponds to the pitch $h$ of $0.47 \mathrm{~nm}$ per main chain glucose residue of the double helix in the crystalline state, determined by X-ray diffraction. ${ }^{14}$ Note that $h=M_{0} / M_{\mathrm{L}}$ with $M_{0}$ being the molar mass per cellobiose unit of the polysaccharide. In this work, to estimate $M_{\mathrm{L}}$ of acid xanthan $\left(\alpha^{\prime}=0\right)$ in $0.01 \mathrm{M}$ aqueous $\mathrm{NaCl}$ at 25 and $75^{\circ} \mathrm{C}$, the molecular weight dependence of zero-shear rate intrinsic viscosity $[\eta]$ was investigated, using the sample X14-2-3 and four other samples, X12-2-3 $\left(\bar{M}_{w}=3.31 \times 10^{5}\right),{ }^{12}$ X9-3 $\left(\bar{M}_{w}=9.3 \times 10^{5}\right), \mathrm{X} 3-5\left(\bar{M}_{w}=1.38 \times 10^{6}\right)$, and X15-2-5 $\left(\bar{M}_{w}=2.14 \times 10^{6}\right)$. The $\bar{M}_{w}$ values for the last three acid samples were calculated from those $\mathrm{e}^{4,5,7}$ in the sodium salt form with the ratio of $M_{0}\left(891 \mathrm{~g} \mathrm{~mol}^{-1}\right)$ of acid xanthan to that $\left(920 \mathrm{~g} \mathrm{~mol}^{-1}\right)$ of $\mathrm{Na}$ xanthan. For comparison, $[\eta]$ data were also taken at $C_{\mathrm{s}}=$ $0.1 \mathrm{M}$, at which the polysaccharide even in the fully ionized state undergoes no appreciable conformation change with increasing $T$ below $80^{\circ} \mathrm{C}^{5}$ 'Huggins' and Mead-Fuoss' plots for both 0.01 and $0.1 \mathrm{M} \mathrm{NaCl}$ solutions at $75^{\circ} \mathrm{C}$ exhibited slight upward deviations from linearity at low $c\left(\eta_{\mathrm{r}} \lesssim 1.1\right)$ owing to proton dissociation accompanying dilution, but the deviations were at most $2 \%$ and ignored in determining $[\eta]$.

\section{RESULTS AND DISCUSSION}

Figure 1 illustrates the temperature dependence of $[\alpha]_{300}$ at different $\alpha^{\prime}$ for sample X14-23 in $0.01 \mathrm{M}$ aqueous $\mathrm{NaCl}$. With increasing $T$, the curves for $\alpha^{\prime}$ above 0.8 sigmoidally rise, indicating that completely or partially neutralized xanthans with $\alpha^{\prime}>0.8$ in the aqueous salt undergo thermally induced conformation changes. We note that, according to our previous analysis, ${ }^{4-6}$ the rise of the curve for $\alpha^{\prime}=1$ is a reflection of partial melting of the xanthan double helix (in the fully ionized state) into a dimerized, expanded coil containing a small number of double-helical residues. As $\alpha^{\prime}$ decreases, the conformation change becomes less pronounced. In particular, the curves for the three lowest $\alpha^{\prime}$, all slightly different at low $T$, are indistinguishable above $55^{\circ} \mathrm{C}$.

Additional measurements on either acid or

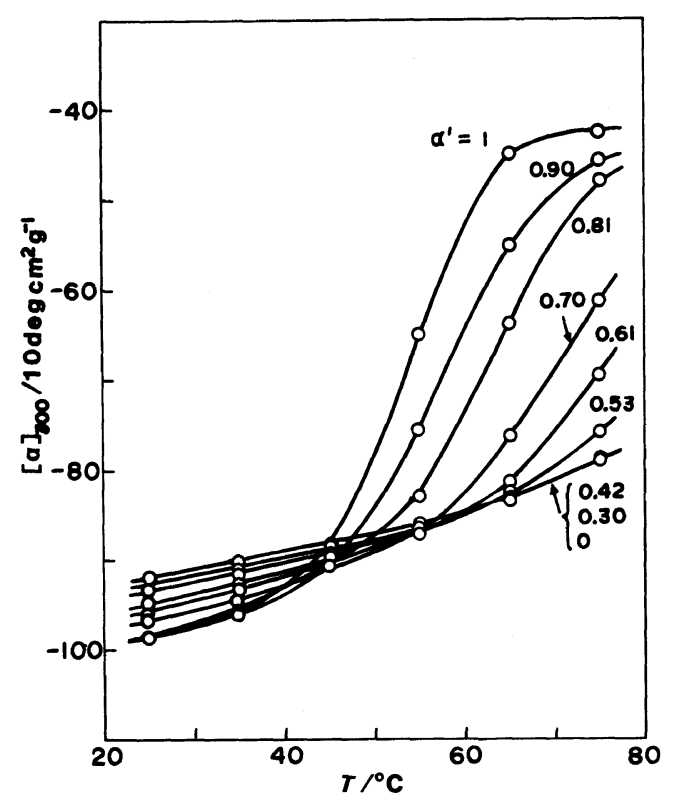

Figure 1. Temperature dependence of $[\alpha]_{300}$ for xanthan sample $\mathrm{X} 14-2-3$ in $0.01 \mathrm{M}$ aqueous $\mathrm{NaCl}$ at indicated degrees of neutralization. $c=1.65 \times 10^{-3}$ $1.73 \times 10^{-3} \mathrm{~g} \mathrm{~cm}^{-3}$. 
$\mathrm{Na}$ xanthan at $C_{\mathrm{s}}=0.1 \mathrm{M}$ yielded $[\alpha]_{300}$ values close to those at $\alpha^{\prime}=0$ and $C_{\mathrm{s}}=0.01 \mathrm{M}$ in the range of $T$ from 25 to $75^{\circ} \mathrm{C}$, especially above $55^{\circ} \mathrm{C}$. Furthermore, these $[\alpha]_{300}$ values at the two $C_{\mathrm{s}}$ did not differ much from previously measured $[\alpha]_{300}$ for $\mathrm{Na}$ xanthan $^{5}$ at a much higher $C_{\mathrm{s}}$ of $0.5 \mathrm{M}$. All these findings combined together suggest that in the temperature range studied, xanthan with an $\alpha^{\prime}$ lower than 0.4 in $0.01 \mathrm{M}$ aqueous $\mathrm{NaCl}$ be predominantly double helical.

The $[\alpha]_{300}$ data in Figure 1 are replotted

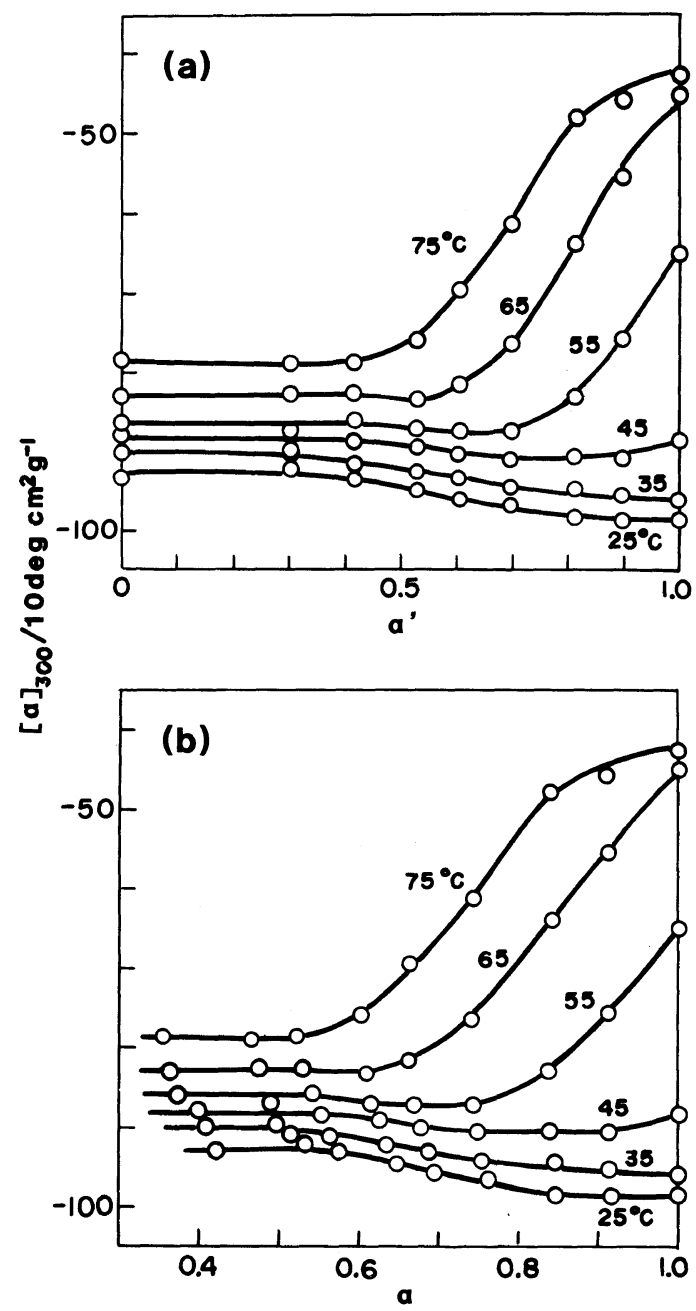

Figure 2. Plots of $[\alpha]_{300}$ against $\alpha^{\prime}$ (a) and against $\alpha$ (b) for sample $\mathrm{X} 14-2-3$ in $0.01 \mathrm{M}$ aqueous $\mathrm{NaCl}$ at indicated temperatures. against $\alpha^{\prime}$ in Figure $2 \mathrm{a}$ and against $\alpha$ in Figure $2 b$. The sigmoidal increases in $[\alpha]_{300}$ with increasing $\alpha^{\prime}$ or $\alpha$ at 65 and $75^{\circ} \mathrm{C}$ demonstrate that acid xanthan in $0.01 \mathrm{M}$ aqueous $\mathrm{NaCl}$ undergoes a conformation change when the charge density is increased at the fixed temperatures.

Figure $3 \mathrm{a}$ depicts the temperature dependence of $\left(\ln \eta_{\mathrm{r}}\right) / c$ at fixed $\alpha^{\prime}$ for sample X14-2-3 in the aqueous salt. All the curves decline with increasing $T$, but in the temperature range examined, only those for $\alpha^{\prime}=1$ and 0.82 appear to reflect the thermally induced conformation change. It should be noted that since the coiled dimer of fully ionized xanthan at

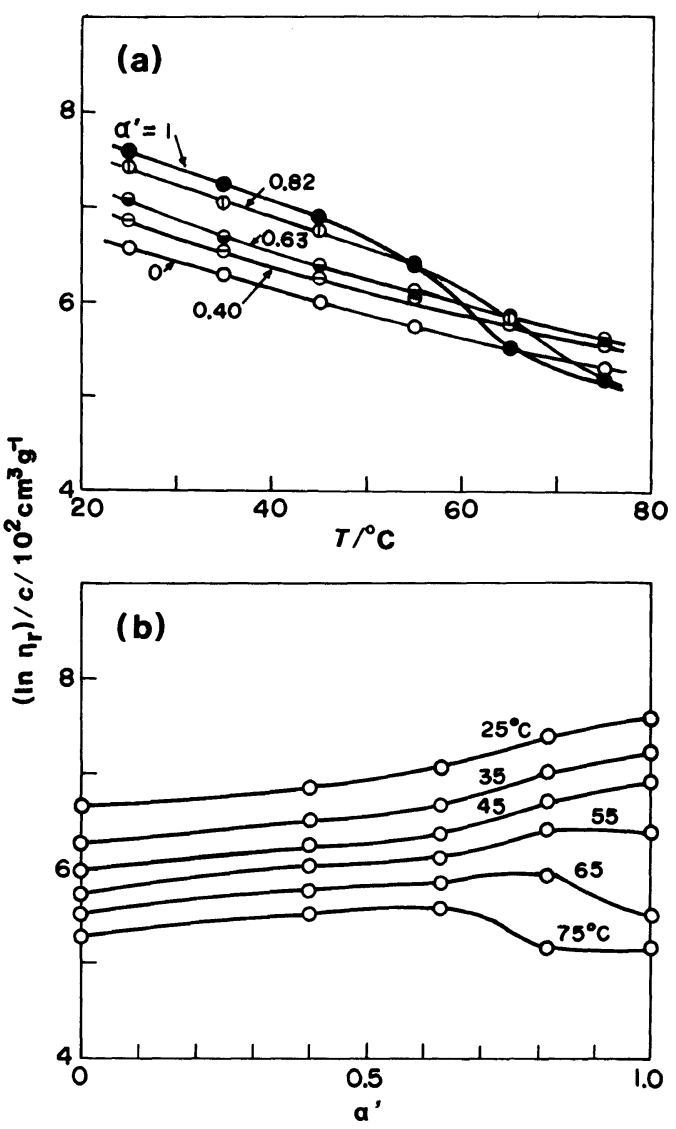

Figure 3. Dependence of $\left(\ln \eta_{\mathrm{r}}\right) / c$ on $T$ at fixed $\alpha^{\prime}$ (a) and that on $\alpha^{\prime}$ at fixed $T$ (b) for sample X14-2-3 in $0.01 \mathrm{M}$ aqueous $\mathrm{NaCl} . \quad c=1.71 \times 10^{-3}-1.79 \times 10^{-3}$ $\mathrm{g} \mathrm{cm}^{-3}$. 


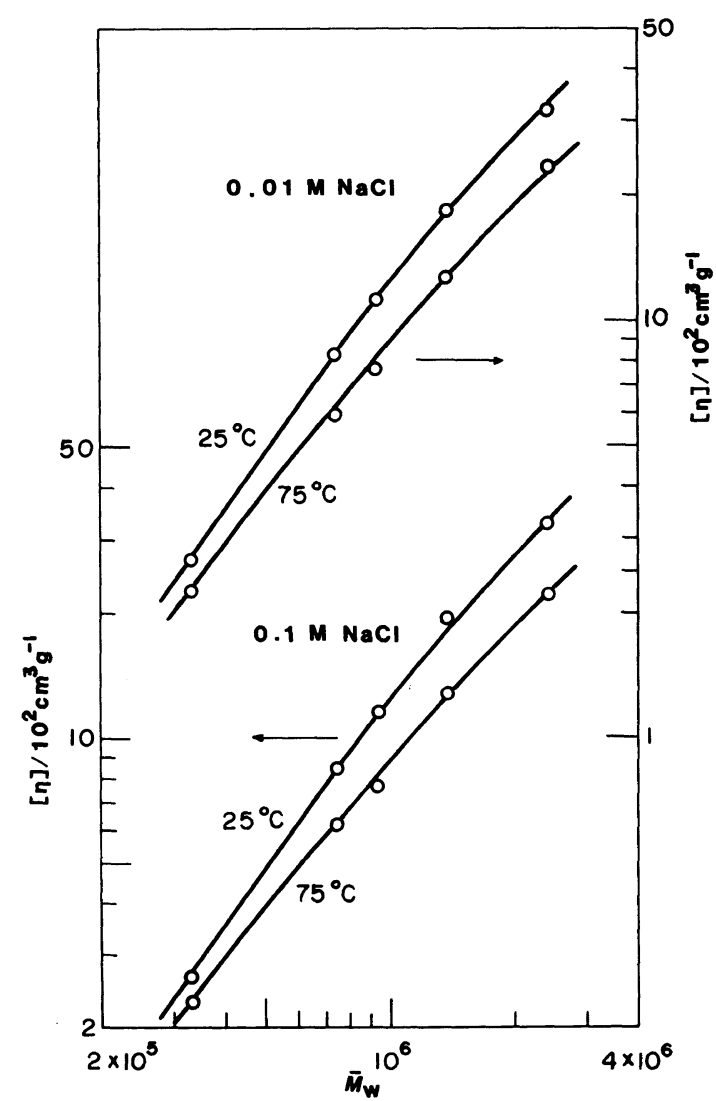

Figure 4. Molecular weight dependence of $[\eta]$ for acid xanthan $\left(\alpha^{\prime}=0\right)$ in 0.01 and $0.1 \mathrm{M}$ aqueous $\mathrm{NaCl}$ at 25 and $75^{\circ} \mathrm{C}$. The solid curves represent the values calculated from the theory of Yamakawa et al. ${ }^{16.17}$ for wormlike cylinders with $M_{\mathrm{L}}=1940 \mathrm{~nm}^{-1}, q=110 \mathrm{~nm}$, and $d=2.0 \mathrm{~nm}$ at $25^{\circ} \mathrm{C}$ and $M_{\mathrm{L}}=1960 \mathrm{~cm}^{-1}, q=70 \mathrm{~nm}$, and $d=2.0 \mathrm{~nm}$ at $75^{\circ} \mathrm{C}$ in both 0.01 and $0.1 \mathrm{M}$ aqueous $\mathrm{NaCl}$.

$80^{\circ} \mathrm{C}$ considerably expands by electrostatic repulsion, ${ }^{4-6}$ the viscosity change is not very remarkable even at $\alpha^{\prime}=1$. The $\left(\ln \eta_{\mathrm{r}}\right) / c$ values at fixed $T$ are plotted against $\alpha^{\prime}$ in Figure 3b, which is to be compared with Figure 2a though the viscosity data refer to finite $c$. The corresponding curves of $\left(\ln \eta_{\mathrm{r}}\right) / c$ vs. $\alpha$ exhibited features similar to those observed in Figure $3 b$.

The molecular weight dependence of $[\eta]$ for acid xanthan in 0.01 and $0.1 \mathrm{M}$ aqueous $\mathrm{NaCl}$ at 25 and $75^{\circ} \mathrm{C}$ is illustrated in Figure 4 . At either temperature, the $[\eta]$ values for all sam- ples in the two solvents are very close to each other. The viscosity exponent is $1.2-1.4$ at $25^{\circ} \mathrm{C}$ and about 1.2 at $75^{\circ} \mathrm{C}$, suggesting that the acid xanthan dimers in the aqueous salts at these temperatures are semiflexible rods. We modeled the dimers by unperturbed wormlike chains, and analyzed the $[\eta]$ data using the Bohdanecký plot ${ }^{15}$ of $\left(\bar{M}_{w}{ }^{2} /[\eta]\right)^{1 / 3}$ vs. $\bar{M}_{w}{ }^{1 / 2}$ based on the theory of Yamakawa et al. ${ }^{16,17}$ for $[\eta]$ of a wormlike cylinder. The theory contains three parameters, $M_{\mathrm{L}}, q$ (the persistence length), and $d$ (the cylinder diameter), but the theoretical $[\eta]$ is insensitive to $d$ unless the cylinder is too short. We assumed $d$ to be $2.0 \mathrm{~nm}$ (the previously estimated value for acid xanthan in $0.01 \mathrm{M}$ aqueous $\mathrm{NaCl}$ containing $0.01 \mathrm{~N} \quad \mathrm{HCl}^{13}$ ), and obtained $M_{\mathrm{L}}=1940 \pm 100 \mathrm{~nm}^{-1}$ and $q=110 \pm 20 \mathrm{~nm}$ at $25^{\circ} \mathrm{C}$ and $M_{\mathrm{L}}=1960 \pm 100 \mathrm{~nm}^{-1}$ and $q=$ $70 \pm 15 \mathrm{~nm}$ at $75^{\circ} \mathrm{C}$ in both 0.01 and $0.1 \mathrm{M}$ aqueous $\mathrm{NaCl}$ from the slopes and intercepts of the Bohdanecký plots (see, for example, ref 7 for the method). The solid curves in Figure 4 actually represent the values calculated from the theory of Yamakawa et al. with these parameter values.

The $M_{\mathrm{L}}$ values of 1940 (at $25^{\circ} \mathrm{C}$ ) and $1960 \mathrm{~nm}^{-1}$ (at $\left.75^{\circ} \mathrm{C}\right)$, which are approximately equal, compare favorably with $1900 \mathrm{~nm}^{-1}$ (in the acid form) corresponding to the established pitch of $0.47 \mathrm{~nm}$ per main chain residue of the xanthan double helix in dilute solution $^{7,9,12}$ or in the crystalline state. ${ }^{14}$ The agreement in $M_{\mathrm{L}}$ supports the suggestion from $[\alpha]_{300}$ that the predominant conformation of acid xanthan in $0.01 \mathrm{M}$ aqueous $\mathrm{NaCl}$ is a double helix in the range of $T$ from 25 to $75^{\circ} \mathrm{C}$. Note that this is also the case in $0.1 \mathrm{M}$ aqueous $\mathrm{NaCl}$. The $q$ of $110 \mathrm{~nm}$ at $25^{\circ} \mathrm{C}$ is comparable to the previously estimated value ${ }^{6}$ of 125 $( \pm 25) \mathrm{nm}$ for fully ionized xanthan in $0.01 \mathrm{M}$ aqueous $\mathrm{NaCl}$ at the same $T$. This finding implies that in the range of $\alpha$ studied, the xanthan double helix in the aqueous salt at $25^{\circ} \mathrm{C}$ is hardly stiffened by increase in charge density. The $q$ of $70 \mathrm{~nm}$ at $75^{\circ} \mathrm{C}$, considerably 


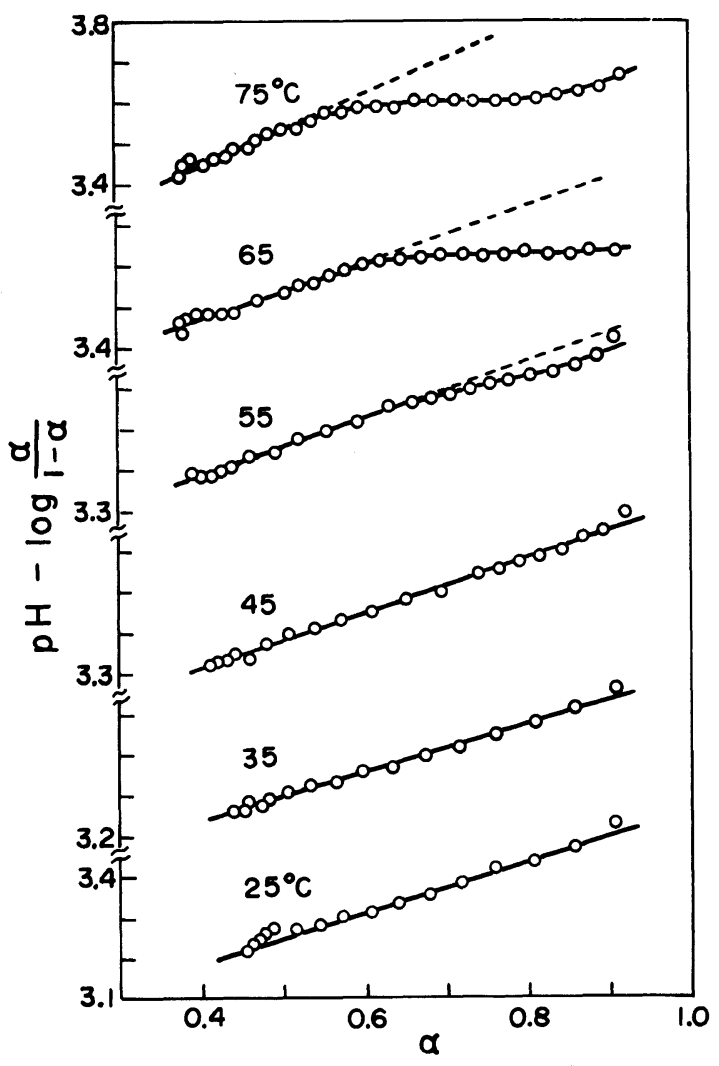

Figure 5. Plots of $\mathrm{pH}-\log (\alpha / 1-\alpha)$ vs. $\alpha$ for xanthan sample $\mathrm{X14-2-3}$ in $0.01 \mathrm{M}$ aqueous $\mathrm{NaCl}$ at indicated temperatures. $c_{\mathrm{p}}, 0.00149 \mathrm{M}$; dashed lines, extension of the linear portions of the curves at low $\alpha$.

smaller than $110 \mathrm{~nm}$ at $25^{\circ} \mathrm{C}$, explains the observed difference in $[\eta]$ between these $T$ in Figure 4 as due primarily to that in the rigidity of the helix.

Since the double-helical conformation of acid xanthan in $0.01 \mathrm{M}$ aqueous $\mathrm{NaCl}$ has been shown to remain almost intact up to the highest $T$ studied, the increases in $[\alpha]_{300}$ with $\alpha$ at fixed $T\left(>50^{\circ} \mathrm{C}\right)$ in Figure $2 \mathrm{~b}$ may be concluded to manifest charge-induced breaking of the double helix. More precisely, the double-helical structure appears to be kept up to a relatively large $\alpha$ (for example, 0.52 at $75^{\circ} \mathrm{C}$ ) and then successively broken with increasing $\alpha$. Below $40^{\circ} \mathrm{C},[\alpha]_{300}$ in the figure rather decreases with increasing $\alpha$. However, since the double-helical structure at $25^{\circ} \mathrm{C}$ is maintained at $\alpha=1,{ }^{4-6}$ the decrease in $[\alpha]_{300}$ at least at $25^{\circ} \mathrm{C}$ has nothing to do with the charge-induced conformation change. We note that in their optical rotation and titration studies, Milas and Rinaudo ${ }^{18}$ showed xanthan in pure water to undergo a certain chargeinduced change but they failed to say what change actually occurs in its conformation.

When the double helix is partially broken, the average distance between charges on the two different chains in the dimer must increase. Since this increase lowers the electrostatic potential energy and hence $\mathrm{pH}-$ $\log (\alpha / 1-\alpha)$, partial helix breaking may be expected to manifest itself also in potentiometric titration curves. Figure 5 shows our titration data at different $T$. The curves at the three lowest $T$ are essentially linear and almost parallel, indicating that no appreciable chargeinduced breaking of the double helix occurs up to $45^{\circ} \mathrm{C}$. This is consistent with the optical rotation data in Figure $2 \mathrm{~b}$. On the other hand, the curves at the higher $T$ bend downward when $\alpha$ exceeds a certain value which is smaller at a higher $T$. Since such an $\alpha$ is close to that above which $[\alpha]_{300}$ sigmoidally increases (Figure 2b), we may conclude that the downward bending of the titration curves is another manifestation of the charge-induced breaking of the xanthan double helix. As discussed elsewhere, ${ }^{13}$ the current titration theory is yet quite unsatisfactory even for almost completely rigid polyacids. Thus, no theoretical analysis of our titration curves was attempted in the present work.

\section{REFERENCES}

1. G. Holzwarth, Biochemistry, 15, 4333 (1976).

2. E. R. Morris, D. A. Rees, G. Young, M. D. Walkinshaw, and A. Darke, J. Mol. Biol., 110, 1 (1977).

3. D. A. Rees, Pure Appl. Chem., 53, 1 (1981).

4. W. Liu, T. Sato, T. Norisuye, and H. Fujita, Carbohydr. Res., 160, 267 (1987).

5. W. Liu and T. Norisuye, Int. J. Biol. Macromol., 10, 44 (1988).

6. W. Liu and T. Norisuye, Biopolymers (in press). 
7. T. Sato, T. Norisuye, and H. Fujita, Polym. J., 16, 341 (1984).

8. T. Sato, S. Kojima, T. Norisuye, and H. Fujita, Polym. J., 16, 423 (1984).

9. T. Sato, T. Norisuye, and H. Fujita, Macromolecules, 17, 2696 (1984).

10. G. Paradossi and D. A. Brant, Macromolecules, 15, 874 (1982).

11. T. Coviello, K. Kajiwara, W. Burchard, M. Dentini, and V. Crescenzi, Macromolecules, 19, 2826 (1986).

12. L. Zhang, W. Liu, T. Norisuye, and H. Fujita, Biopolymers, 26, 333 (1987).

13. L. Zhang, T. Takematsu, and T. Norisuye, Macromolecules, 20, 2882 (1987).

14. K. Okuyama, S. Arnott, R. Moorhouse, M. D. Walkinshaw, E. D. T. Atkins, and Ch. Wolf-Ullish,
"Fiber Diffraction Methods," A. D. French and K. H. Gardner, Ed., ACS Symp. Ser. No. 141, American Chemical Society, Washington, D.C., 1980, p 411.

15. M. Bohdanecký, Macromolecules, 16, 1483 (1983); see also S. V. Bushin, V. N. Tsvetkov, E. B. Lysenko, and V. N. Emelyanov, Vysokomol. Soedin., Ser. A, 23, 2494 (1981).

16. H. Yamakawa and M. Fujii, Macromolecules, 7, 128 (1974).

17. H. Yamakawa and T. Yoshizaki, Macromolecules, 13, 633 (1980).

18. M. Milas and M. Rinaudo, "Solution Properties of Polysaccharides," D. A. Brant, Ed., ACS Symp. Ser. No. 150, American Chemical Society, Washington, D.C., 1981, p 25. 